\title{
An imported case of vaccine-derived poliovirus type 2 , Spain in the context of the ongoing polio Public Health Emergency of International Concern, September 2021
}

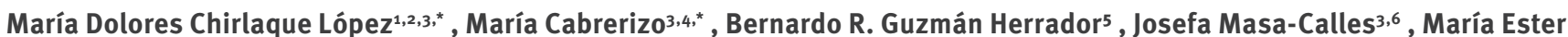

Alarcón-Linares ${ }^{1}$, Ana Allende ${ }^{7}$, Esteban Aznar Cano ${ }^{5}$, María Isabel Barranco Boada ${ }^{1}$, Elena Cantero Gudino ${ }^{8}$, Sonia FernándezBalbuena ${ }^{5}$, Ana Fernández Dueñas ${ }^{8}$, María Dolores Fernández-García ${ }^{4}$, Laura García Hernández ${ }^{9}$, Visitación García Ortúzar ${ }^{10}$

, Noemí López-Perea ${ }^{3,6}$, Eduardo Martínez-Salcedo ${ }^{2,11}$, Antonio Moreno-Docón ${ }^{2,12}$, María Ordobás Gavín ${ }^{13}$, Inmaculada Rodero

Garduño $^{13}$, Maria José Sierra Moros ${ }^{5,14}$, Fernando Simón Soria ${ }^{3,5}$, Aurora Limia Sánchez ${ }^{8}$, Berta Suárez Rodríguez ${ }^{5}$

1. Department of Epidemiology, Murcia Regional Health Council, Murcia, Spain

2. IMIB-Arrixaca, Murcia University, Murcia, Spain

3. CIBER in Epidemiology and Public Health (CIBERESP), Madrid, Spain

4. National Polio Laboratory, National Centre for Microbiology, Instituto de Salud Carlos III, Madrid, Spain

5. Coordinating Centre for Health Alerts and Emergencies (CCAES), Directorate General of Public Health, Ministry of Health, Madrid, Spain

6. National Centre of Epidemiology, Carlos III Health Institute, Madrid, Spain

7. Research Group on Microbiology and Quality of Fruit and Vegetables, Food Science and Technology Department, CEBAS-CSIC, Espinardo, Murcia, Spain

8. Immunization Programme Area, Directorate General of Public Health, Ministry of Health, Madrid, Spain

9. Epidemiology and Prevention Service, Public Health General Direction, Canary Islands Health Service, Santa Cruz de Tenerife, Spain

10. Lorca Public Health Service, Murcia, Spain

11. Neuropediatric Unit, Department of Paediatrics, University Hospital Virgen of Arrixaca, Murcia, Spain

12. Microbiology Service. Hospital Clínico Universitario Virgen de la Arrixaca, Murcia, Spain

13. Sub-Directorate General of Epidemiology, Community of Madrid, Spain

14. CIBER in Infectious Diseases (CIBERINFEC), Madrid, Spain

* These authors contributed equally to this work and share first authorship

Correspondence: Bernardo R. Guzmán Herrado (bguzman@sanidad.gob.esu)

Citation style for this article:

Chirlaque López María Dolores, Cabrerizo María, Guzmán Herrador Bernardo R., Masa-Calles Josefa, Alarcón-Linares María Ester, Allende Ana, Aznar Cano Esteban, Barranco Boada María Isabel, Cantero Gudino8 Elena, Fernández-Balbuena Sonia, Fernández Dueñas Ana, Fernández-García María Dolores, García Hernández Laura, García Ortúzar Visitación, López-Perea Noemí, Martínez-Salcedo Eduardo, Moreno-Docón Antonio, Ordobás Gavín María, Rodero Garduño Inmaculada, Sierra Moros Maria José, Simón Soria Fernando, Limia Sánchez Aurora, Suárez Rodríguez Berta. An imported case of vaccine-derived poliovirus type 2, Spain in the context of the ongoing polio Public Health Emergency of International Concern, September 2021. Euro Surveill. 2021;26(50):pii=2101068. https://doi. org/10.2807/1560-7917.ES.2021.26.50.2101068

The monthly retrospective search for unreported acute flaccid paralysis (AFP) cases conducted as a complementary component of the Spanish AFP surveillance system identified a case of AFP in a child admitted in Spain from Senegal during August 2021. Vaccinederived poliovirus 2 was identified in the stool in September 2021. We present public health implications and response undertaken within the framework of the National Action Plan for Polio Eradication and the Public Health Emergency of International Concern.

In mid- to end-September 2021, a case of vaccinederived poliovirus type 2 (VDPV2) was detected by the National Polio Laboratory in the National Centre for Microbiology (CNM) in Spain. We present the public health implications and rapid response to this event within the framework of the National Action Plan for Polio Eradication (NAPPE) [1] and the ongoing Public Health Emergency of International Concern (PHEIC) on the risk of international spread of polio [2].

\section{Case description}

A child below the age of 6 years arrived in Murcia, south-eastern Spain, from Senegal at the beginning of August 2021. The patient was admitted to a hospital on a scheduled basis to continue supportive treatment of an acute flaccid paralysis (AFP) with unknown aetiology and with onset of symptoms in Senegal at the beginning of July 2021. In the second week of August, the patient was discharged from hospital after clinical improvement with the diagnosis of AFP secondary to acute anterior meningomyeloradiculitis because of enterovirus infection. During admission, enterovirus was found in a respiratory sample (later characterised as coxsackievirus B4) and in faeces. During the first days of September, the case stayed with a local family before returning to Senegal.

\section{Case detection}

The NAPPE requires surveillance for early notification and virological study of all AFP cases in children under 15 years of age [3]. However, the AFP surveillance 
Classification of contacts of the case with vaccine-derived poliovirus type 2 and measures undertaken, Spain, September 2021

\begin{tabular}{|c|c|c|c|}
\hline \multirow{2}{*}{ Classification } & \multirow{2}{*}{ Definition/type of exposure } & \multicolumn{2}{|l|}{ Measures } \\
\hline & & Collection of stool samples & Vaccination \\
\hline \multicolumn{4}{|l|}{ Close contact } \\
\hline I & $\begin{array}{c}\text { Cohabitants and non-cohabitants with intense direct } \\
\text { physical contact i.e. helped with personal hygiene, helped } \\
\text { with feeding, played with physical contact }\end{array}$ & \multirow{2}{*}{$\begin{array}{l}\text { Collection and analysis of two } \\
\text { faecal specimens collected }>24 \mathrm{~h} \\
\text { apart }\end{array}$} & \multirow[t]{2}{*}{ One dose of IPV vaccine } \\
\hline II & $\begin{array}{c}\text { Non-cohabitants with prolonged direct physical contact } \\
\text { i.e. rehabilitation care }\end{array}$ & & \\
\hline \multicolumn{4}{|l|}{ Casual contact } \\
\hline III & Stayed in the same room without direct physical contact & \multirow{2}{*}{$\begin{array}{c}\text { Collection of two faecal specimens } \\
\text { collected }>24 \mathrm{~h} \text { apart; analysis if } \\
\text { positive samples were identified in } \\
\text { close contacts }\end{array}$} & \multirow{2}{*}{$\begin{array}{l}\text { Considered if positive } \\
\text { samples were } \\
\text { identified in close } \\
\text { contacts }\end{array}$} \\
\hline IV & $\begin{array}{c}\text { Any other person who has not had physical contact but } \\
\text { has had some contact with the case i.e. family member } \\
\text { who visited the household for a short time }\end{array}$ & & \\
\hline
\end{tabular}

IPV: inactivated polio vaccine.

procedure was not initiated during the admission of this case. As a complementary activity of the AFP surveillance, the NAPPE states that regional public health departments (RPHD) should communicate any unreported AFP cases identified through a retrospective search in the paediatric and neurology hospitalisation wards located in their region to the National Centre of Epidemiology (CNE) on a monthly basis. Notification of zero cases is included in the system [3]. In this context, the AFP case hospitalised in August 2021, which had gone unreported, was identified by the RPHD in the Region of Murcia and notified to CNE at the beginning of September.

It was then possible to retrieve a stool sample of the case that was sent to the CNM. The presence of poliovirus (PV) was investigated by cell culture following World Health Organization (WHO) standard procedures $[4,5]$. A cytopathic effect was observed on the inoculated RD and L2OB cells. In mid- to end-September, the virus was isolated and characterised as PV2 using the intratypic differentiation assay according to the recommended protocol [6]. Sequencing of the complete VP1 genomic region indicated that, according to the WHOadopted criteria [7], it was a vaccine-derived poliovirus 2 (VDPV2) strain since it was $5.1 \%$ divergent from the $\mathrm{PV}_{2}$ Sabin strain in the VP1 sequence. Results were further confirmed by the Regional Reference Laboratory of the WHO/Europe for Poliomyelitis [8] at the Robert Koch Institute, Berlin, Germany.

According to the statement of the Thirtieth International Health Regulations (IHR) Emergency Committee on the international spread of PV and the ongoing PHEIC, Senegal was classified as a country with circulating

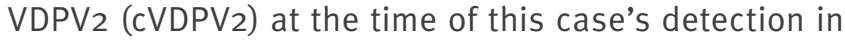
Spain. According to the WHO, the most recent detection in Senegal had been in mid-September 2021 [2]. The recent cVDPV2 outbreak detected in Senegal was linked to ongoing transmission in other areas of West Africa [9]. The case's vaccination card showed four doses of oral polio vaccine and one dose of inactivated polio vaccine (IPV) received during the first year of life.

\section{National and international coordination}

Following notification of the case, a national technical support group (GAT) that included all actors with a role in the management of the event was convened by the Coordinating Centre for Health Alerts and Emergencies (CCAES). Its mandate was to keep all stakeholders updated about the development of the event, discuss the information available and provide technical advice on response actions. The GAT included representatives of the CCAES and the immunisation programme area at the Ministry of Health, the CNM, the CNE and the RPHD of the Region of Murcia. A regional technical support group with all stakeholders involved in the response at the regional level was also convened in Murcia. After identifying that six contacts of the case resided in two additional regions, Madrid and the Canary Islands, representatives from RPHD of these two regions were also included in the GAT. In addition, and after proposal by the GAT, the Director General of Public Health at the Ministry of Health convened the Response Coordinating Committee (RCC) one week later (end-September). This included representatives at a higher strategic level. Actions proposed by the GAT were discussed and endorsed by the RCC.

On the same day the GAT was convened, the CCAES reported the case to the WHO Regional Office for Europe and communicated the case to the IHR focal point in Senegal, requesting additional information on the background of the case as well as on the epidemiological situation of cVDPV2. Following WHO standard operating procedures [10], the alert was classified as an event with no evidence of transmission in Spain in which VDPV2 had been detected in a human case with AFP. The case was also communicated via the Early Warning and Response System of the European Union [11]. 


\section{TABLE 2}

Distribution of contacts of a case with vaccine-derived poliovirus type 2 by region, Spain, September 2021 $(\mathrm{n}=42)$

\begin{tabular}{|l|c|c|c|}
\hline Region & Close contact & Casual contact & Total \\
\hline Murcia & 19 & 17 & 36 \\
\hline Madrid & 0 & 5 & 5 \\
\hline Canary Islands & 1 & 0 & 1 \\
\hline Total & 20 & 22 & 42 \\
\hline
\end{tabular}

Measures undertaken to respond to the event The following measures were undertaken within the framework of the NAPPE.

Identification and classification of contacts, collection of stool samples and vaccination Individuals who had been in contact with the case in Spain were classified into four categories according to their level of exposure, and specific actions were planned (Table 1). In Spain, there is a high immunity against polio in the general population $[12,13]$ and since 1998 , vaccination coverage at a national level has been higher than $95 \%$ [14]. In addition, coverage rates at the local level in the Region of Murcia range between 94\% and $96 \%$ (data not shown). Considering this situation, and after receiving confirmation that all contacts were vaccinated according to the national immunisation programme, the RCC decided to recommend vaccination of close contacts with one dose of IPV.

Depending on the results of the close contacts' stool cultures, the recommendations would be reviewed in order to consider the administration of an additional dose of IPV and/or extend the vaccination recommendations. A review of potential unvaccinated individuals and possible susceptible groups was carried out in the relevant area.

Twenty close contacts and 22 casual contacts were identified, 36 in Murcia and six in other Spanish regions (Table 2). All close contacts received one dose of the IPV vaccine.

\section{Virological analysis in contacts and in wastewater}

By mid- to end-November 2021, 40 stool samples from 20 close contacts had been analysed in the CNM with the same standard cell culture methods used for the AFP case, and CVDPV 2 infection was excluded for all of them. The samples of casual contacts (III and IV) are currently being studied for enterovirus only by PCR. In addition, four raw wastewater samples taken from two different entry points of the wastewater treatment plant from the area where the case had stayed on 2 different days during mid- to end-September were analysed. The samples were processed and concentrated at the CEBAS-CSIC laboratory and testing for the presence of enterovirus was carried out in the CNM by cell culture and PCR techniques. All of them were PV-negative, but non-polio enteroviruses were detected by PCR: an echovirus 3 in samples collected on the first day and an enterovirus $A$ in samples collected on the second day.

Virological results in close contacts and wastewater samples suggest no onward PV transmission following this event in Spain.

\section{Enhanced surveillance with retrospective and prospective search for suspected cases}

A retrospective search for potential additional cases has been conducted through a review of all admissions in all hospitals in the Region of Murcia since August 2021. A daily zero-reporting system was established to ensure prospective and timely reporting of all suspected cases from all hospitals in the Region of Murcia until the closure of the event. Two children with Guillain-Barré syndrome were identified and the AFP surveillance protocol was applied, resulting negative for PV.

\section{Ethical statement}

Acute flaccid paralysis is a notifiable disease in Spain. No ethical approval was sought as this study describes the public health actions undertaken under the framework of the NAPPE following the detection of an imported case of AFP because of a vaccine-derived $\mathrm{PV}_{2}$ in Spain. Written consent for the case report was obtained from the legal guardian of the child.

\section{Discussion}

The WHO European Region was declared polio-free in 2002 [15]. In light of the ongoing circulation of wild PV type 1 and CVDPV worldwide and ongoing use of live attenuated vaccines in some countries, there is a risk of introduction of wild PV, or vaccine-derived PV in countries declared polio-free such as Spain. Given the high standards of sanitation and hygiene, the high vaccination coverage and high level of immunity against $\mathrm{PV}$, together with good detection and response capacities to events related to polio, the risk of transmission of PV in Spain is estimated to be low [16]. However, in the context of the NAPPE and the ongoing PHEIC, there is no room for complacency. Although indicators show that the AFP surveillance system in Spain is of good quality, its sensitivity has decreased in recent years, possibly because of a lower perception of the risk of poliomyelitis as a consequence of the absence of polio cases [17].

\section{Conclusion}

This event has shown the importance of maintaining an optimal coordination among all the components that are part of the NAPPE and reminds us that in order to sustain a status free of PV circulation we must maintain and strengthen PV surveillance systems for early detection. This includes increasing awareness among clinicians, clinical microbiologists, public health 
specialists and other actors with a role in this system as well as maintaining good vaccination coverage.

\section{Conflict of interest}

None declared.

\section{Authors' contributions}

MDCL led the investigation in the Region of Murcia. MC led the laboratory investigation at central level. BSR coordinated the national technical support group. BRGH drafted the first version of the manuscript. MDCL, MC, BGH, JM-C, MEAL, EAC, MIBB, ECG, SF-B, AFD, MDF-G, LGH, NL-P, MOG, IRG, MJSM, FSS, ALS, and BSR are members of the national technical group. AA, AM-D, EM-S and VGO had a role in the event management in the Region of Murcia. All authors revised the manuscript.

\section{References}

1. Ministry of Health, Social Services and Equality. Plan de acción en España para la erradicación de la poliomielitis. [Action plan in Spain for Polio eradication]. Madrid: Ministry of Health, Social Services and Equality; 2016. Spanish. Available from: https://www.mscbs.gob.es/profesionales/saludPublica/ prevPromocion/PlanPolio/docs/Plan_erradicacion_ poliomielitis.pdf

2. World Health Organization (WHO). Statement of the thirtieth Polio IHR Emergency Committee. Geneva: WHO; 23 Nov 2021. Available from: https://www.who.int/news/item/23-11-2021statement-of-the-thirtieth-polio-ihr-emergency-committee

3. Masa-Calles J, Torner N, López-Perea N, Torres de Mier MV, Fernández-Martínez B, Cabrerizo M, et al. Acute flaccid paralysis (AFP) surveillance: challenges and opportunities from 18 years' experience, Spain, 1998 to 2015. Euro Surveill. 2018;23(47):1700423. https://doi.org/10.2807/1560-7917. ES.2018.23.47.1700423 PMID: 30482263

4. World Health Organization (WHO). Polio Laboratory Manual, 4th edition. Geneva: WHO; 2004. Available from: http://apps. who.int/iris/bitstream/10665/68762/1/WHO_IVB_04.10.pdf

5. World Health Organization (WHO). An alternative test algorithm for poliovirus isolation and characterization. Polio Laboratory Manual 4th edition. Geneva: WHO; 2004: Available from: http://polioeradication.org/wp-content/uploads/2017/05/ NewAlgorithmForPolioviruslsolationSupplement1.pdf

6. Gerloff N, Sun H, Mandelbaum M, Maher C, Nix WA, Zaidi S, et al. Diagnostic assay development for Poliovirus eradication. J Clin Microbiol. 2018;56(2):e01624-17. https://doi.org/10.1128/ JCM.01624-17 PMID: 29212703

7. Global Polio Eradication Initiative (GPEI). Classification and reporting of vaccine-derived polioviruses (VDPV). GPEI guidelines. Geneva: GPEI; 2016. Available from: https:// polioeradication.org/wp-content/uploads/2016/09/ Reporting-and-Classification-of-VDPVs_Aug2016_EN.pdf

8. Robert Koch Institut (RKI). WHO Reference Laboratories. Regional Reference Laboratory of the WHO/Europe for Poliomyelitis. Berlin: RKI; 2021. [Accessed: 13 Dec 2021]. Available from: https://www.rki.de/EN/Content/Institute/ International/reference_labs/ref_lab_node.html

9. World Health Organization (WHO). Statement of the twentyeighth polio IHR emergency committee. Geneva: WHO; 21 May 2021. Available from: https://www.who.int/news/item/21-052021-statement-following-the-twenty-eighth-ihr-emergencycommittee-for-polio

10. World Health Organization (WHO). Standard operating procedures; Responding to a poliovirus event or outbreak version 3. Geneva: WHO; Jan 2019. Available from: https:// polioeradication.org/wp-content/uploads/2016/07/sop-poliooutbreak-response-version-20193101.pdf

11. European Centre for Disease Prevention and Control (ECDC). Early Warning and Response System of the European Union (EWRS). Stockholm: ECDC; 2021. Available from: https://www.ecdc.europa.eu/en/publications-data/ early-warning-and-response-system-european-union-ewrs

12. Limia Sánchez A, Olmedo Lucerón C, et al. 2nd seroprevalence study in Spain, 2017-2018. Rev Esp Salud Pública. 2021;95:e202103059. Spanish. Available from: https://www.
mscbs.gob.es/biblioPublic/publicaciones/recursos_propios/ resp/revista_cdrom/VOL95/C_ESPECIALES/RS95C_202103059. pdf

13. Ministry of Health, Social Services and Equality. 2 Estudio de Seroprevalencia en España. [2nd seroprevalence study in Spain]. Madrid: Ministry of Health, Social Services and Equality; 2020. Spanish. Available from: https://www. mscbs.gob.es/profesionales/saludPublica/prevPromocion/ vacunaciones/comoTrabajamos/docs/EstudioSeroprevalencia_ EnfermedadesInmunoprevenibles.pdf

14. Ministry of Health, Social Services and Equality. Coberturas de vacunación. Datos estadísticos. [Vaccine coverage. Statistical data]. Madrid: Ministry of Health, Social Services and Equality. [Accessed: 20 Nov 2021]. Spanish. Available from: https://www.mscbs.gob.es/profesionales/saludPublica/ prevPromocion/vacunaciones/calendario-y-coberturas/ coberturas/home.htm

15. World Health Organization Regional Office for Europe (WHO/Europe). Certification of the Region's polio-free status in 2002. Copenhagen: WHO/Europe. [Accessed: 20 Nov 2021]. Available from: https://www.euro.who.int/ en/health-topics/communicable-diseases/poliomyelitis/ activities/certification-and-maintenance-of-polio-freestatus-in-the-european-region/european-regionalcommission-for-the-certification-of-poliomyelitis-eradication/ certification-of-the-regions-polio-free-status-in-2002

16. World Health Organization Regional Office for Europe (WHO/ Europe). Report of the 33rd Meeting of the European Regional Certification Commission for Poliomyelitis Eradication. Copenhagen: WHO/Europe. 2019. Available from: https://www. euro.who.int/_data/assets/pdf_file/0016/414025/33rd-RCCeng.pdf

17. National Centre of Epidemiology and National Centre for Microbiology Instituto de Salud Carlos III (ISCIII). Plan de acción en España para la Erradicación de la Poliomielitis. Vigilancia de la Parálisis Flácida Aguda y Vigilancia de Enterovirus en España, Informe año 2020. [Action Plan in Spain for polio eradication. Surveillance of acute flaccid paralysis and surveillance of enterovirus in Spain. 2020 report]. Madrid: ISCIII. 5 Nov 2021. Spanish. Available from: https://www.isciii. es/QueHacemos/Servicios/VigilanciaSaludPublicaRENAVE/ EnfermedadesTransmisibles/Documents/archivos\%20A-Z/ POLIO/Resultados_Vigilancia_Polio/Informes_Anuales_Polio/ Informe_PFA_EV_2020_web.pdf

\section{License, supplementary material and copyright}

This is an open-access article distributed under the terms of the Creative Commons Attribution (CC BY 4.0) Licence. You may share and adapt the material, but must give appropriate credit to the source, provide a link to the licence and indicate if changes were made.

Any supplementary material referenced in the article can be found in the online version.

This article is copyright of the authors or their affiliated institutions, 2021. 